\title{
Nephronophthisis in Finland: epidemiology and comparison of genetically classified subgroups
}

\author{
Sirpa A la-M ello ${ }^{1}$, Olli Koskimies ${ }^{2}$, Juhani R apola ${ }^{2}$ and $\mathrm{H}$ elena $\mathrm{K}$ ääriäinen ${ }^{3}$ \\ ${ }^{1}$ D epartment of M edical G enetics, U niversity of $\mathrm{H}$ elsinki \\ ${ }^{2} \mathrm{H}$ ospital for Children and A dolescents, U niversity of $\mathrm{H}$ elsinki \\ ${ }^{3}$ The Family Federation of Finland, $\mathrm{H}$ elsinki, Finland
}

\begin{abstract}
Nephronophthisis - medullary cystic kidney disease is a progressive chronic tubulointerstitial nephritis leading to terminal renal failure. A bout two thirds of the patients with familial juvenile nephronophthisis, an autosomal recessive disease, have a homozygous deletion at the gene locus on 2q13. Through a nationwide search, 59 patients were ascertained in Finland. The incidence was 1:61 800 live births when calculated over a 20-year period. 0 f the patients, 17 came from four families showing dominant inheritance and 37 patients from 28 apparently recessive families when classified by family history, clinical features or presence of a deletion on 2q13. Two were considered as new dominant mutations; three sporadic patients could not be classified. The most significant difference between the patients with deletions, patients without deletions but having recessive family history, and patients belonging to families with dominant inheritance was the age at first symptoms, at the start of dialysis and at transplantation. These facts will be of help in determining the mode of inheritance of a sporadic patient without a deletion.
\end{abstract}

Keywords: nephronophthisis; medullary cystic disease; epidemiology; tubulointerstitial nephritis; $2 q 13$ deletion

\section{Introduction}

The term familial juvenile nephronophthisis was introduced in 1951 when Fanconi et al described seven children in two large kindreds having a progressive renal disease with contracted kidneys leading to death during childhood. ${ }^{1}$ A ctually, a sporadic patient with an identical kidney disease had been reported in 1945 by Smith and G raham, who used the term medullary cystic kidney disease. ${ }^{2}$ This latter terminology was used by $\mathrm{H}$ ogness and B urnell in 1954 to describe a disease with

Correspondence: A la-M ello Sirpa, Department of M edical Genetics, U niversity of Helsinki, P.O. B ox 21 (H aartmaninkatu 3) FIN 00014-Helsinki, Finland. Tel: +358 9191 26361; Fax: +358 9191 26677; E-mail: Sirpa.A laMello@helsinki.fi

R eceived 13 March 1998; revised 10 September 1998; accepted 14 September 1998 similar pathology in adults. ${ }^{3}$ The terminology has been confusing; later these two diseases have been thought to represent the same entity and the term nephronophthisis-medullary cystic disease, refers to this., ${ }^{4,5}$

However, there exists a very rare form of nephronophthisis which is autosomal dominant and leads to endstage renal disease between the third and fifth decades of life. ${ }^{6-8} U$ sually, the term medullary cystic disease refers to the dominant form, and nephronophthisis to the recessive form. In this study we use nephronophthisis for both forms but specify the term with the additional clarifications - recessive, dominant and sporadic.

The first symptoms and signs leading to end-stage renal disease are polydipsia and polyuria caused by decreased urinary concentrating ability, anaemia and growth retardation. The kidneys become contracted 
when reaching the end-stage and macroscopic cysts of variable size can be seen at the corticomedullary border or in the medulla. ${ }^{9}$ The light microscopic changes are not specific and they resemble those of any chronic tubulointerstitial nephritis. The thickening of the tubular basement membrane is probably the most characteristic histopathologic change in nephronophthisis. ${ }^{10}$

Tapetoretinal degeneration is the most common of the extrarenal manifestations of nephronophthisis. This association, the Senior-Loken syndrome, has been estimated to account for $10-15 \%$ of the patients. ${ }^{11,12}$ 0 ther associated manifestations are liver fibrosis, coneshaped epiphyses, cerebellar ataxia, calcification of basal ganglia, and pancreatic lipomatosis leading to insufficiency. ${ }^{13-15}$

The pathogenesis behind nephronophthisis is unknown. A locus for recessive nephronophthisis (NPH locus) was assigned by linkage analysis to chromosome $2 q 13 .{ }^{16-18}$ The families with the Senior-L oken syndrome and also some of the families with recessive nephronophthisis without extrarenal manifestations did not show linkage to N PH 1 locus thus confirming genetic heterogeneity. ${ }^{16,17}$ Later, homozygous deletions of approximately $250 \mathrm{~kb}$ in the NPH 1 region were detected in most patients showing linkage to $2 q 13 .{ }^{19}$ R ecently, two genes were identified in the deleted area. Of these, the NPHP 1 gene consists of at least twenty exons and its transcript of $4.5 \mathrm{~kb}$ has been detected in human skeletal muscle, heart, kidney and pancreas by northern blot analysis. ${ }^{20,21}$

In this nationwide study we examined the epidemiology and genealogy of nephronophthisis as well as the clinical course of the disease. By studying the family history and the presence or absence of deletions on $2 q 13$ we defined etiologically homogeneous groups of patients. The clinical course and especially the prognosis of the renal disease is described for the first time in genetically classified patient groups.

\section{Patients and Methods}

Nephronophthisis leads to terminal renal failure and renal replacement therapy. Figure 1 shows the three approaches for ascertainment of the patients. The primary search yielded 111 patients whose hospital records were studied. The following selection criteria were used for inclusion in the study.

1. A renal biopsy specimen from at least one affected individual of each family had to be available showing characteristic changes of chronic tubulointerstitial nephritis, especially thickening of tubular basement membranes.

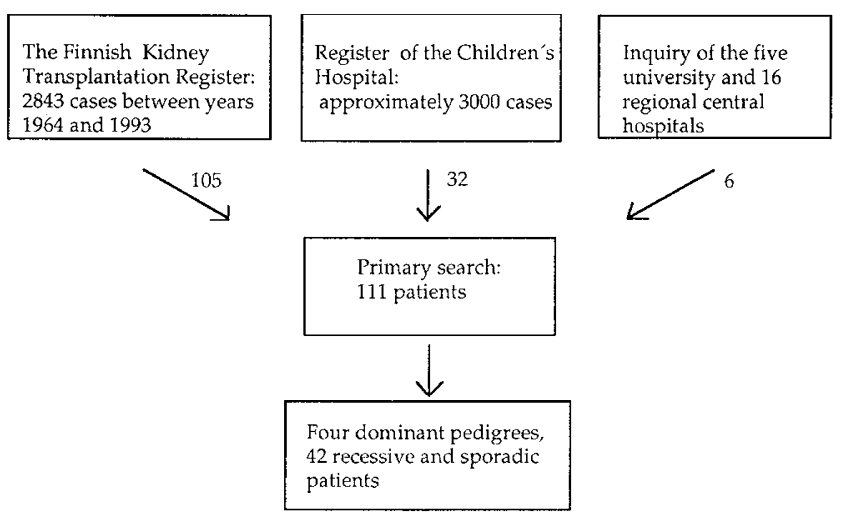

Figure 1 The approaches for ascertainment of the patients. The Finnish K idney Transplantation Register was founded in 1964 when renal transplantations were started in Finland. R egister of the Children's H ospital, kept since 1974, comprises children with chronic renal disease with or without renal insufficiency and kidney transplantation

2. Patients with urinary tract malformation, especially vesicoureteric reflux, systemic disease, infection, or medication that may cause chronic tubulointerstitial nephritis were excluded.

3. Documentation of at least one of the following symptoms was obligatory: polydipsia, polyuria, anaemia, or growth retardation.

4. The urinary specific gravity had to be constantly below 1.010. Patients with nephritic sediment, proteinuria and haematuria were excluded, except low grade proteinuria, usually below $0.3 \mathrm{~g} / \mathrm{l}$.

5. The renal disease had to be chronic and progressive by nature.

The parents and/or patients in the 18 families that gave consent to deletion analysis were contacted and their family histories requested. The birthplaces of the parents and grandparents of all the patients were found through the population register. The ancestors of each patient were traced back 4-6 generations to discover consanguinity or remote relationship between the patients. The disease was considered dominant if it occurred in at least two consecutive generations, recessive if unaffected parents had more than one affected child, and sporadic if there was only one affected person in the family.

A segregation analysis of the recessive and sporadic families was carried out with corrections for truncate complete ascertainment by A pert's a priori method, and for truncate single ascertainment by omitting one affected child from each sibship. ${ }^{22}$

The members of the 18 families with patients having either recessive or sporadic nephronophthisis were evaluated with primers $765 \mathrm{~F} 2 \mathrm{~L}$ and $804 / 6$ for the presence or absence of deletions of chromosome $2 q 13 .{ }^{23}$ A DNA sample was available from at least one patient in each family/pedigree.

A II available kidney biopsy specimens were histologically re-examined by one of our research group (J $R$ ). 


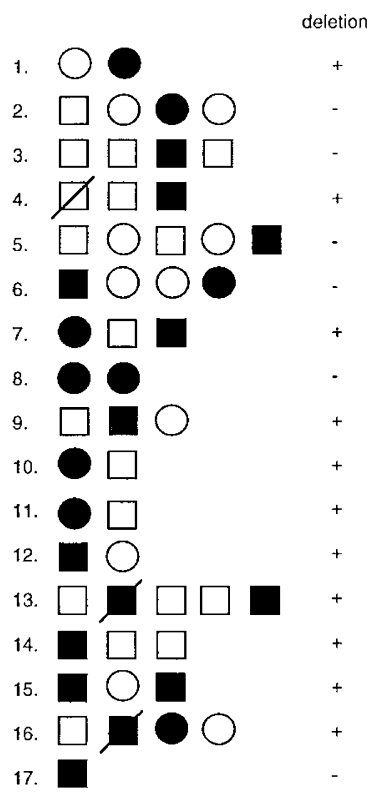

Figure 2 The 33 sibships of recessive and sporadic nephronophthisis with 42 affected and 61 unaffected. Solid circles and squares represent affected and open circles and squares represent unaffected females and males respectively. A t least one patient from each of families 1-18 was studied for the existence of deletion; + represents deletion and - represents no deletion. Family 19 belongs to the same pedigree as Family 9 and thus represents those families having deletions

For statistical analyses we used the $M$ ann-W hitney $U$ test. Values are expressed as means $\pm S E M$. A P value $\leq 0.05$ was considered significant.

\section{Results}

\section{Epidemiology}

A Itogether 59 patients fulfilled the selection criteria. Of these, 17 belonged to four families with dominant inheritance, 19 came from families showing recessive inheritance, and 23 were sporadic. The sibships of recessive and sporadic families are shown in Figure 2. Interfamilial relationships were found between five families (9 and 29, 14-16) forming two pedigrees. The four dominant pedigrees are seen in Figure 3. The incidence of nephronophthisis when calculated for a 20-year period (1963-1982) was 1:61 800 live births.

\section{Forming of Groups I, II and III}

Table 1 shows the division of 42 recessive and sporadic patients into different categories as concerns deletion study. Homozygous deletions of chromosome 2q13 were found in familes: 1, 4, 7, 9-16, 18 and 19 (Figure 2). ${ }^{23}$ Consequently, the 15 patients from these families form an etiologically homogeneous patient group with recessive nephronophthisis, G roup I.

The eight patients from families 2, 3, 5, 6, 8 and 17 (Figure 2) did not have deletions. Of them, two pairs of siblings in families 6 and 8 can be assumed to have the autosomal recessive form too, but according to the haplotype analysis they are not linked to chromosome 2q13. ${ }^{23}$ They form G roup II.

Deletion studies were not performed in the dominant families which form the third group, Group III. No samples were available for deletion studies from one recessive family (27), with three patients and 13 families with sporadic patients.

\section{Clinical Findings and Progression of the Disease}

The main first symptoms or signs of the disease in Groups I, II and III are presented in Table 2. A naemia was the most common finding in Group I and hypertension in G roup III. B oth patients of family 6 in G roup II were examined because of occasional bloody diarrhoea and anaemia at the ages of 11 and 17 respectively; histologically they were diagnosed as having ulcerative colitis.

The clinical and laboratory findings of the patients of the three groups at the time of diagnosis are shown in Table 3. Serum creatinine values of the patients of
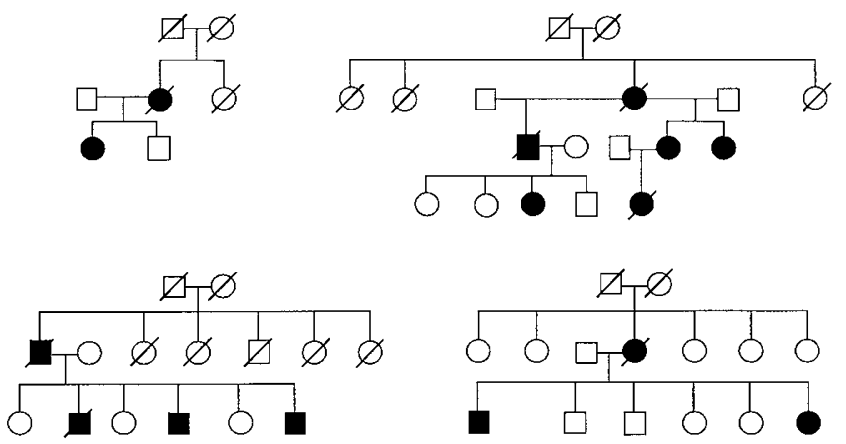

Figure 3 The four pedigrees with dominant nephronophthisis

Table 1 The mode of inheritance according to family history and deletion studies on chromosome $2 q 13$ in 57 patients with nephronophthisis

\begin{tabular}{llll}
\hline & \multicolumn{3}{c}{ Family history } \\
\cline { 2 - 4 } & Recessive & Sporadic & D ominant \\
\hline N umber of patients & 19 & 23 & 17 \\
D eletion found & 12 & 6 & \\
No deletion & 4 & 4 & \\
N ot studied & 3 & 13 & 17 \\
\hline
\end{tabular}


Table 2 First symptoms or signs of the disease of the patients with nephronophthisis having homozygous deletion on $2 q 13$ (G roup I), without deletion but recessive by family history (G roup II), and with dominant inheritance (G roup III)

\begin{tabular}{lrll}
\hline & \multicolumn{3}{c}{ G roup I G roup II G roup III } \\
\cline { 2 - 4 } N umber & 15 & 4 & 8 \\
\hline M ain first symptoms: & 10 & 3 & 1 \\
A naemia & 2 & & \\
G rowth retardation & 2 & & \\
Polydipsia/polyuria & 1 & 1 & 4 \\
H ypertension & & & 2 \\
C ccasional proteinuria & & 1 \\
By chance on routine screening & & \\
\hline
\end{tabular}

G roup I varied between 124 and $580 \mu \mathrm{mol} / \mathrm{l}$, in G roup II between 153 and $463 \mu \mathrm{mol} / \mathrm{l}$, and in G roup III between 120 and $292 \mu \mathrm{mol} / \mathrm{l}$. One patient in Group I had proteinuria at the time of diagnosis with advanced renal insufficiency. Serum electrolytes were within normal range at the time of diagnosis. We have previously published a detailed analysis of erythropoesis in recessive and sporadic nephronophthisis. ${ }^{24}$ The ages at first symptoms or signs of the disease and progression of the disease to terminal renal failure are presented in Table 4. In Group I the disease presented at an earlier age and progression was more rapid than in the other Groups.

In Group I, altogether 13 patients have received renal transplants. Two patients are not yet in terminal renal failure. Five of the patients received parental transplants. Seven of the patients are presently managing well after their first transplantation, one after the second, one after the third and one after the fourth transplantation. Two patients are waiting for their third transplants. Three patients had died before transplantations were available (families 16 and 19, Figure 2).

Three of the four patients in $\mathrm{G}$ roup II have received their first renal transplants and are managing well. Splenectomy was performed on the oldest patient of family 6 one month after transplantation because of leukopenia, thrombocytopenia and splenomegaly. $\mathrm{H}$ is younger sister has not undergone transplantation because of tuberculosis.

In Group III, five patients are managing well after first transplantations, and one after the second. O ne patient has slow progressive chronic rejection after his first transplantation. O ne patient died of myocardial infarction three years after the first transplantation at the age of 54 years.

Table 3 Clinical and laboratory findings (mean \pm SE M) of the patients with nephronophthisis at the time of the diagnosis having deletion (G roup I), without deletion but recessive by family history (Group II), and with dominant inheritance (G roup III). Statistically significant $P$ values were found between G roups I and III

\begin{tabular}{|c|c|c|c|c|}
\hline & Group I & Group II & Group III & $P$ \\
\hline N umber & 15 & 4 & 8 & \\
\hline H aemoglobin (g/l) & $9.1 \pm 1.0$ & $9.8 \pm 9.7$ & $12.5 \pm 1.6$ & 0.0002 \\
\hline $\mathrm{H}$ aematocrit $(\%)$ & $27 \pm 3.4$ & $28 \pm 3.1$ & $32 \pm 3.5$ & 0.03 \\
\hline $\mathrm{MCV}(\mathrm{fl})$ & $81.4 \pm 4.0$ & $89.2 \pm 4.6$ & $87.0 \pm 1.4$ & \\
\hline $\mathrm{MCH}(\mathrm{pg})$ & $28 \pm 1$ & \pm 2 & \pm 0 & \\
\hline Sedimentation rate & \pm 24.0 & \pm 29.9 & \pm 18.0 & \\
\hline Serum creatinine $(\mu \mathrm{mol} / \mathrm{l})$ & \pm 149 & \pm 137 & 183 & \\
\hline G lomerular filtration rate $\left(\mathrm{ml} / \mathrm{min} / 1.73 \mathrm{~m}^{2}\right)$ & $24.1 \pm 17.7$ & $20.4 \pm 5.1$ & $55.8 \pm 29.8$ & 0.02 \\
\hline U rinary specific gravity & $1.004 \pm 8.2 \times 10^{-4}$ & $1.007 \pm 1.1 \times 10^{-3}$ & $1.009 \pm 1.3 \times 10^{-3}$ & 0.004 \\
\hline Systolic blood pressure $(\mathrm{mmH} \mathrm{g})$ & \pm 13.4 & \pm 11.8 & \pm 20.5 & 0.01 \\
\hline D iastolic blood pressure (mmH g) & \pm 11.9 & \pm 8.5 & \pm 15.2 & 0.005 \\
\hline
\end{tabular}

M CV = M ean corpuscular volume; M CH = M ean corpuscular haemoglobin

Table 4 Progression of the disease of the patients with nephronophthisis having deletion ( $\mathrm{G}$ roup I), without deletion but recessive by family history (G roup II), and with dominant inheritance (G roup III) (means \pm SE M)

\begin{tabular}{lccc}
\hline & G roup I & G roup II & G roup II \\
\cline { 2 - 4 } N umber & 15 & 4 & 8 \\
\hline A ge at first symptoms (years) & $7.9 \pm 2.9$ & $19.8 \pm 6.2^{\mathrm{b}}$ & $29.6 \pm 8.3^{\mathrm{d}}$ \\
A ge at diagnosis/biopsy & $9.4 \pm 3.0$ & $21.1 \pm 6.6^{\mathrm{b}}$ & $32.1 \pm 8.9^{\mathrm{d}}$ \\
Progression (years) & $4.3 \pm 3.1$ & $6.1 \pm 2.4^{\mathrm{a}}$ & $6.9 \pm 3.7$ \\
A ge at dialysis & $12.6 \pm 3.4$ & $24.8 \pm 6.2^{\mathrm{b}}$ & $36.6 \pm 10.5^{\mathrm{e}}$ \\
A ge at transplantation & $13.1 \pm 3.6$ & $27.8 \pm 7.1^{\mathrm{c}}$ & $38.5 \pm 10.3^{\mathrm{e}}$ \\
\hline
\end{tabular}

${ }^{\mathrm{a}}$ Progression $=$ time between the first symptoms and the beginning of dialysis; ${ }^{b} \mathrm{P}=0.003 ;{ }^{\mathrm{C}} \mathrm{P}=0.009 ;{ }^{\mathrm{d}} \mathrm{P}=0.0002 ;{ }^{\mathrm{e}} \mathrm{P}=0.0003$ 


\section{Renal Histopathological Findings}

The following histological changes were seen in all the kidney specimens: atrophic tubules, located far from each other, and remarkable thickening of the tubular basement membranes, especially in the distal tubules. Dilated tubules were often seen to form cysts of various sizes. Lymphocyte infiltrations and marked interstitial fibrosis were present either focally or diffusely. G lomeruli were either normal or sclerotic in variable degree. Vascular changes were usually absent. I n conclusion, no histological differences were seen between the renal biopsies of the patients in Groups I, II, III and the patients who were not studied for the existence of the deletion.

\section{Extrarenal Findings}

$\mathrm{H}$ epatic dysfunction was not seen in any of the patients and serum transaminases were normal in all the patients in Groups I, II and III. Liver ultrasonographs had been performed several times on 13 patients of $\mathrm{G}$ roup I and at least once on all the patients of $\mathrm{G}$ roups II and III with normal findings. Two patients in Group II had ulcerative colitis without a liver disease.

The electrophysiological studies, comprising electroretinograms and visual evoked potentials were performed on seven patients with either recessive or sporadic nephronophthisis at the Department of $\mathrm{O}$ phthalmology, $\mathrm{H}$ elsinki U niversity $\mathrm{H}$ ospital, and the results were normal.

Several radiological investigations had been performed on eleven patients of Group I and all four patients of Group II for evaluation of bone age and bone mineralisation. Bone abnormalities referring to syndromic forms of nephronophthisis were not seen, whereas signs of renal osteodystrophy were a common finding at advanced renal failure.

\section{Classification of the Rest of the Patients not belonging to Groups I, II and III in the First Phase}

A Itogether 39 out of the original 59 patients could be classified into Groups I, II and III by family history and deletion analysis. In the following, the remaining 20 patients are classified according to the symptoms, signs and pattern of their disease into G roups I, II and III.

A II three sons of family 27 had died because of terminal uraemia under 10 years of age, and 12 out of 17 sporadic patients had their first symptoms of the disease between the ages of 6 and 12 years and developed terminal uraemia between the ages of 9 and
16 years. Thus, these 15 patients most likely represent recessive nephronophthisis with deletions (Group I). Three sporadic patients developed terminal uraemia between the ages of 20 and 25 years and could not be classified. Two sporadic patients were over 35 years of age when developing terminal uraemia and they could represent new dominant mutations (Group III).

\section{Segregation Analysis}

In the families with deletions the proportion of affected sibs was 0.268 (SE 0.027) when corrected for truncate complete ascertainment by A pert's a priori method and 0.200 (SE 0.086) when corrected for truncate single ascertainment. In the families with no deletions or who were not studied for the existence of the deletion, the proportion of affected sibs was 0.250 (SE 0.032) when corrected for truncate complete ascertainment by A pert's a priori method and 0.154 (SE 0.065) when corrected for truncate single ascertainment. The sporadic patients who could not be classified or were probable new dominant mutations were excluded from the segregation analysis. The birthplaces of the grandparents of the patients are shown in Figure 4. No parental consanguinity was found in any of the families.

\section{Discussion}

No reliable figures concerning the incidence of nephronophthisis/medullary cystic disease have been published. In this nationwide search we found altogether 59 patients fulfilling the generally accepted criteria. ${ }^{16,17}$ B ecause of the centralised treatment of terminal renal failure in Finland, the primary search for patients with clinical features compatible with nephronophthisis must have been practically complete. It is possible that some, especially adult patients, escaped our series because the nephronophthisis may have led to terminal renal failure with few symptoms and no renal biopsy sample. A nother cause for bias is that perhaps all the patients born in the early 1980s have not yet presented with typical symptoms and signs of nephronophthisis. $\mathrm{N}$ ephrologists at the university and central hospitals were contacted to find early cases. In this study the incidence of nephronophthisis was 1:62000 live-born when calculated for the 20-year period 1963-1982.

A total of 37 patients from 28 families could be classified by family history, deletion analysis or clinical picture as having the recessive form of nephronophthisis. The incidence of the recessive form was 
1:80000 live-born when calculated for the 20-year period 1963-1982. Seventeen patients from four pedigrees had dominant nephronophthisis, and two sporadic patients were classified on clinical grounds as new dominant mutations. Three sporadic patients could not be classified. There were no syndromic cases. Corresponding proportions from other systemically collected patient materials are not known.

When performing segregation analysis separately on families with deletions and families without deletions or who were not examined, the proportion of affected siblings when corrected for truncate complete ascer-

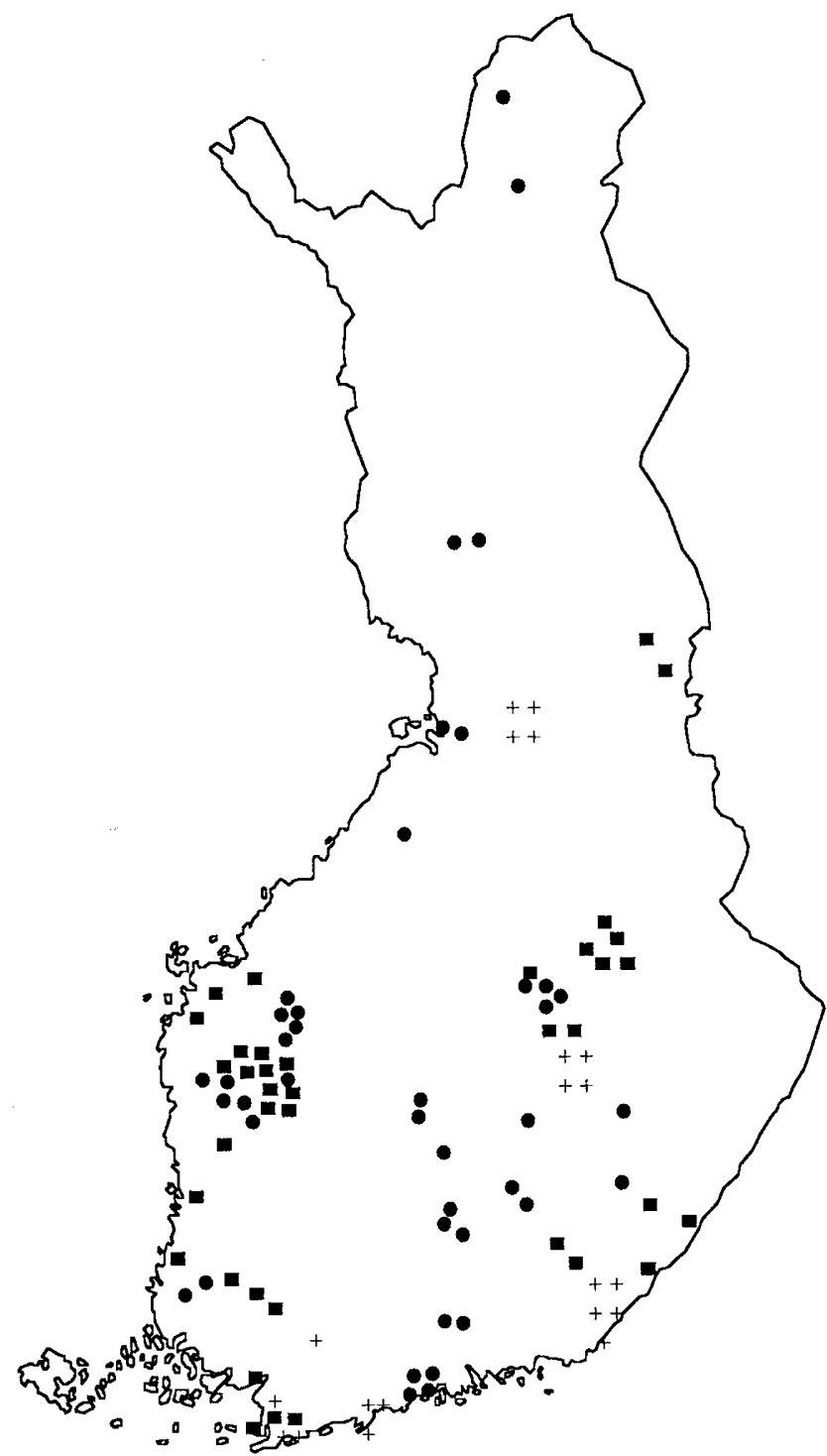

Figure 4 The birthplaces of the grandparents of the patients with nephronophthisis having deletions (solid circles), without deletions $(+)$, and those who were not in the deletion analysis (solid squares). tainment by A pert's a priori method was in concordance with autosomal recessive inheritance in both groups. However, it was lower in the non-deletion/not studied group when corrected for truncate single ascertainment. In spite of this, our conclusion is that most of these patients also represent recessive nephronophthisis. This is supported by the discovery that the birthplaces of the grandparents of the patients with deletions and those not studied are geographically situated in the same regions showing some accumulation in sparsely populated areas in western and central eastern Finland (Figure 4). It is possible, however, that we may have classified some patients with new dominant mutations erroneously as recessive ones.

L inkage and haplotype analyses and deletion studies have confirmed the heterogeneity of nephronophthisis. ${ }^{16,17,23}$ Previous studies have not revealed any clinical or histological features that would allow discrimination between deletion-positive and deletion-negative patients. ${ }^{25}$ In this study we found three clinical presentations of nephronophthisis. When comparing the patients with deletions in Group I with patients of G roup II, both representing recessive nephronophthisis, we found a statistically significant difference in the ages at the first symptoms, the time of diagnosis and the beginning of the dialysis treatment (Table 4). H owever, the corresponding ages were even higher among those in G roup III with dominant inheritance. Thus, onset at very young age, before the age of 15 , suggests recessive disease and homozygous deletions are likely to be found in these patients. In a sporadic patient, the onset of the disease at 25 years of age or over, suggests the dominant form, whereas onset between 20 and 25 years of age fits both recessive and dominant forms. Hypertension before advanced renal failure suggests the dominant form, as does occasional mild proteinuria.

The finding of a homozygous deletion confirms the diagnosis of recessively inherited nephronophthisis. In these patients renal biopsy is not necessary. A ge of onset, clinical details and course of the disease may help to categorise the patients without deletions to determine the mode of inheritance and to predict the progression of the disease.

\section{Acknowledgements}

We wish to thank Docent Kirsi Setälä for the neuroophthalmological examinations of the patients and $\mathrm{MS}$ Sinikka Lindh for technical help with drawing the pedigrees. This work was supported by grants from the $K$ idney Foundation and the Finnish Society of Nephrology. 


\section{References}

1 Fanconi $\mathrm{G}, \mathrm{H}$ anhart $\mathrm{E}, \mathrm{A}$ lbertini $\mathrm{A}$, U hlinger $\mathrm{E}$, D olivo $\mathrm{G}$, Prader A : D ie familiäre juvenile Nephronophthise. Helv Paediatr A cta 1951; 6: 1-49.

2 Smith CH, G raham J B: Congenital medullary cysts of the kidneys with severe refractory anemia. A $\mathrm{m} \mathrm{J} \mathrm{D} \mathrm{is} \mathrm{Child}$ 1945; 69: 370-378.

3 Hogness J R, Burnell J M : M edullary cysts of the kidney. A rch Intern Med 1954; 93: 355-366.

4 M ongeau J G, Worthen H G : Nephronophthisis and medullary cystic disease. A m J M ed 1967; 43: 345-355.

5 Strauss M B, Sommers SC: M edullary cystic disease and familial juvenile nephronophthisis. N Engl J M ed 1967; 277: 863-864.

6 G oldman SH, Walker SR, M erigan TC, G ardner KD, B ull J M C : Hereditary occurrence of cystic disease of the renal medulla. N E ngl J Med 1966; 274: 984-992.

$7 \mathrm{G}$ ardner KD: Evolution of clinical signs in adult onset cystic disease of the renal medulla. A nn Intern M ed 1971; 74: 47-54.

8 Collan Y, Sipponen P, H aapanen E, L indahl J, Jokinen EJ, $\mathrm{H}$ jelt L: H ereditary nephronophthisis with a life span of three decades. Virchows A rch (A) 1977; 376: 195-208.

9 K leinknecht C, Habib R : Nephronophthisis. In: Cameron J C, D avison A M, Grunfeld J P, K ers KNS, R itz E (eds). Textbook of Clinical N ephrology. O xford U niversity Press: Oxford, England, 1992, pp 2188-2197.

10 Waldherr R, L ennert T, Weber H-P, Födisch HJ, Schärer $\mathrm{K}$ : The nephronophthisis complex. Virchows Arch (A) 1982; 394: 235-254.

11 Senior B, Friedmann A I, Braupo JL: Juvenile familial nephropathy with tapetoretinal degeneration. A new oculorenal dystrophy. Am J O phthalmol 1961; 52: 625-633.

12 L oken A C, H anssen O, Halvorsen S, Jolster N J: Hereditary renal dysplasia and blindness. A cta Paediatr 1961; 50: 177-184.

13 Boichis $H$, Passwell J, David R, Miller $H$ : Congenital hepatic fibrosis and nephronophthisis. Q J M ed 1973; 42: 221-233.

14 Mainzer F, Saldino R M , O zonoff M B, M inagi H : Familial nephropathy associated with retinitis pigmentosa, cerebellar ataxia and skeletal abnormalities. A m J M ed 1970; 49: 556-562.
15 R aafat F, M orita M, Lau M, Taylor C-M, White RHR: Juvenile nephronophthisis with calcification of basal ganglia and pancreatic insufficiency. A rch Pathol $L$ ab M ed 1988; 112: 630-633.

16 A ntignac $\mathrm{C}, \mathrm{A}$ rduy $\mathrm{CH}, \mathrm{Beckmann} \mathrm{J}$ S et al: A gene for familial juvenile nephronophthisis (recessive medullary cystic kidney disease) maps to chromosome $2 p$. N at $\mathrm{G}$ enet 1993; 3: 342-345.

17 Hildebrandt F, Singh-Sawhney I, Schnieders B et al: $M$ apping of a gene for familial juvenile nephronophthisis: Refining the map and defining flanking markers on chromosome 2. A m J H um G enet 1993; 53: 1256-1261.

18 M edhioub $M$, C herif $D, B$ enessy $F$ et al: R efined mapping of a gene (NPH1) causing familial juvenile nephronophthisis and evidence of genetic heterogeneity. $G$ enomics 1994; 22: 296-301.

19 Konrad M, Saunier S, H eidet $L$ et al: $L$ arge homozygous deletions of the $2 q 13$ region are a major cause of juvenile nephronophthisis. H um M ol G enet 1996; 5: 367-371.

20 Hildebrandt $F, O$ tto $E$, Rensing $C$, Nothwang $H G$ Vollmer $\mathrm{M}, \mathrm{A}$ dolphs J, $\mathrm{H}$ anusch $\mathrm{H}$, B randis $\mathrm{M}$ : A novel gene encoding an SH3 domain protein is mutated in nephronophthisis type 1 . N at G enet 1997; 17: 149-153.

21 Saunier S, Calado J, Heilig $R$ et al: A novel gene that encodes a protein with a putative src homology 3 domain is a candidate gene for familial juvenile nephronophthisis. H um Mol G enet 1997; 6: 2317-2323.

22 Li CC: H uman genetics: principles and methods. M CG rawHill: New York, 1961.

23 A la-M ello S, Sankila E-M , Koskimies O, de la Chapelle A, $\mathrm{K}$ ääriäinen $\mathrm{H}$ : M olecular studies in Finnish patients with familial juvenile nephronophthisis exclude a founder effect and support a common mutation causing mechanism. J Med G enet 1998; 35: 279-283.

24 A la-M ello S, Kivivuori SM, Rönnholm KA R, Koskimies 0 , Siimes MA : M echanism underlying early anaemia in children with familial juvenile nephronophthisis. Pediatr Nephrol 1996; 10: 578-581.

25 Hildebrandt F, Strahm B, N othwang HG et al (M embers of the A PN Study G roup: M olecular genetic identification of families with juvenile nephronophthisis type 1 : R ate of progression to renal failure. Kidney Int 1997; 51: 261-269. 